\title{
The effects of an escape contingency upon running wheel and one-way avoidance learning?
}

ROBERT C. BOLLES, NEAL E. GROSSEN, and GEORGEE. HARGRAVE, University of Washington, Seattle, Wash. 98105

Rats were given avoidance training for 60 trials in a running wheel or 30 trials in a one-way apparatus. For different groups the consequences of failing to avoid in a given trial were escapable shock or inescapable shock of fixed duration. The results indicate that the escape contingency makes no contribution to avoidance learning in these two situations.

It is becoming clear that the empirical rules of avoidance learning are relatively situation specific, so that the critical parameters and conditions for learning in one situation may be of little consequence in another situation. For example, Bolles, Stokes, \& Younger (1966) found that the escape contingency was an important factor in the acquisition of the shuttlebox avoidance response $\left(R_{a}\right)$, contributing roughly as much to the speed of acquisition as either the avoidance of shock or the CS-termination contingency. In the acquisition of the running wheel $R_{a}$, on the other hand, most of the variation among groups was attributable to whether shock could be avoided, and the escape contingency was not a significant factor.
As far as the situation-specific importance of the escape contingency is concerned, this finding of our earlier study could be criticized on the grounds that total exposure to shock was not comparable under the different conditions that were used. The escape contingency was eliminated by using a very short shock, and avoidance learning under these conditions was compared with that obtained under the usual conditions in which, following a failure to avoid, the shock came on and stayed on until terminated by the escape response $\left(R_{e}\right)$. It could be argued that $S$ s run under the latter condition not only had an escape contingency, they also experienced a greater total amount of shock, which might have some biasing effect upon avoidance performance. The present study is concerned with discrediting this argument. We will show that for some $R_{a} s$ the escape contingency makes no contribution to avoidance learning, and that this is true throughout a range of total amounts of shock. SUBJECTS

The Ss were 96 female rats of Long-Evans descent, approximately 120 days old.

\section{APPARATUS}

Two kinds of apparatus were used. One was a short runway $4 \frac{1}{2} \mathrm{in}$. wide, $5 \mathrm{in}$. high, and 28 in. long, including a 12-in. start box. The second apparatus was a 14-in. diam running wheel, similar to that described by
Bolles et al (1966). $R_{a}$ was defined automatically by a photocell system that detected a half-revolution of the wheel. Shock was provided by a dc source of $900 \mathrm{~V}$ connected in series with a 1.5-megohm resistor to sets of nine stainless-steel floor grids between which were connected neon bulbs. The chief effect of the bulbs was to establish a constant voltage drop of $58 \mathrm{~V}$ between adjacent grids. The $\mathrm{CS}$ was an $85-\mathrm{dB}$ white noise plus, in the case of the runway, the opening of the start-box door.

\section{PROCEDURE}

Six groups of eight Ss were run in each apparatus. All Ss were trained for a single session of 30 trials in the runway or 60 trials in the wheel. In the runway, S had to be picked up and replaced in the starting box, and the intertrial interval was necessarily somewhat variable, but it averaged approximately $45 \mathrm{sec}$. In the wheel the intertrial interval was programmed by tape with intervals ranging from 30 to $60 \mathrm{sec}$, with a mean of $45 \mathrm{sec}$. The CS came on $5 \mathrm{sec}$ before a scheduled shock and overlapped the shock. An $R_{a}$ during the first 4.5 sec of this interval avoided shock and immediately terminated the CS. Following this 4.5 -sec interval the door to the start box was closed for the inescapable runway $S s$ and the shock presented for its scheduled duration. The only difference in the running wheel was that, of course, the inescapable-shock Ss could not be prevented from running even though shock termination was not dependent upon their doing so. All Ss were treated alike with regard to the opportunity for making an $R_{a}$, and the consequences of $R_{a}$ were always the same, viz, avoiding shock. The six groups were treated differently only following a failure to avoid. Four of the six.

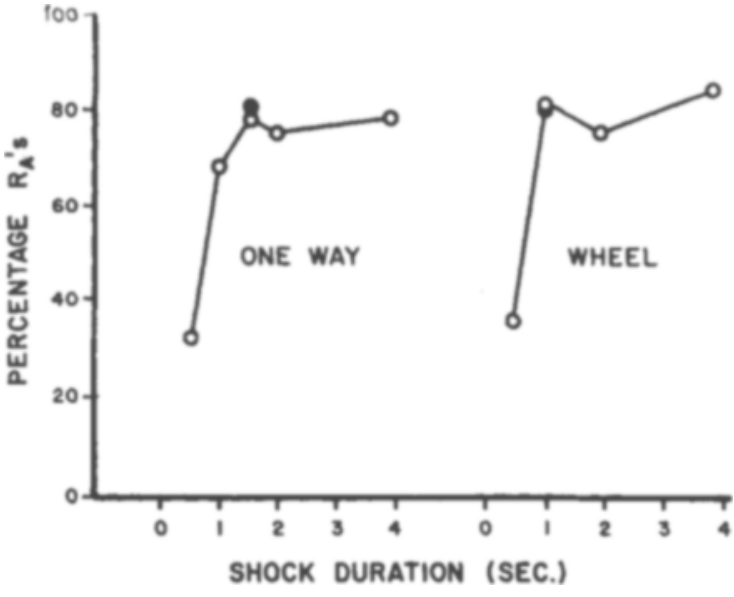

Fig. 1. Median percentage avoidance responses $\left(R_{g} s\right)$ in two situations as a function of shock duration on nonavoidance trials. The Ss were trained 60 trials in the running wheel and 30 trials in the one-way apparatus.

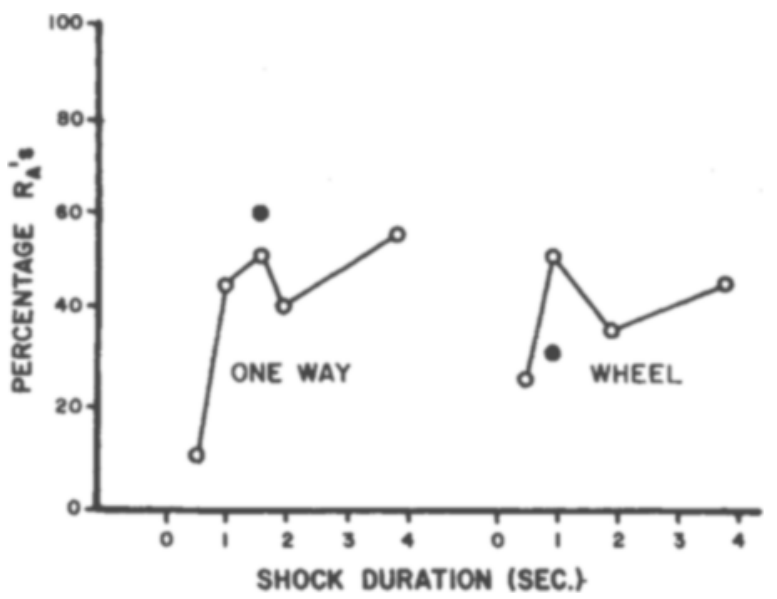

Fig. 2. Median percentage $R_{a} s$ in the first 10 trials in the two situations. 
groups in each apparatus had an inescapable shock of fixed duration of $0.5,1,2$, or $4 \mathrm{sec}$. The fifth group had the normal escape contingency, and the sixth group had inescapable shock of varied duration, the duration on any one trial being the mean of the duration effected by $S$ s with the escape contingency. In effect, these last Ss, the matched group, were yoked to the escape group. In the one-way apparatus, running time, and hence shock duration, fell in a few trials to a minimal value close to $1.5 \mathrm{sec}$. In the wheel, running times were very close to $1.0 \mathrm{sec}$, even at the beginning of training. When it became apparent that the yoked group would duplicate the $1-\sec$ group, it was abandoned, and the $1-\mathrm{sec}$ group taken to be an appropriate substitute.

\section{RESULTS AND DISCUSSION}

The median number of $R_{a}$ s for each group over the course of training is given in Fig. 1 . It is obvious that shock duration on nonavoidance trials has no effect upon overall avoidance performance except in the case of the shortest shocks used, i.e., $0.5 \mathrm{sec}$. At this minimal value of shock there was a serious loss in both kinds of apparatus, perhaps because such short shocks fail to produce an adequate level of motivation. It could be argued that performance in most cases was so good that there was little room for any improvement attributable to the possibility of escaping shock on nonavoidance trials. That is, the high overall level of performance might mask a small but real contribution of the escape contingency to avoidance learning. One way to answer this question is to examine the relative performance early in training before performance has approached its ceiling. Such data for the first 10-trial block are shown in Fig. 2. The results from the first trials are naturally more variable than the overall scores, but the same general pattern is apparent: There is some loss of performance, or failure to learn with the shortest checks, but over most of the range of duration of inescapable shock, performance is indistinguishable from the performance of Ss that escape shock. The conclusion must be that, in these two avoidance learning situations, the escape contingency makes no apparent contribution to the acquisition of $R_{a}$. The reason this is so, we would suggest, is that the response that is required of $S$ in both of these situations is an effective species-specific defense reaction. In both the wheel and the one-way apparatus, running permits the rat to get away, in some sense at least, and running is acquired as an $R_{a}$ in these situations purely and simply because running does permit $S$ to get away. According to this account (Bolles, in press) it is immaterial that the situation is arranged so that running actually avoids shock, and as we have found here, it is also immaterial whether the situation is arranged so that the same running response can also escape shock. Under these conditions $R_{a}$ is rapidly acquired apparently without benefit of what is ordinarily considered to be one of the important reinforcement contingencies.

\section{REFERENCES}

BOLLES, R. C. Avoidance and escape learning: Simultaneous acquisition of different responses. Journal of Comparative \& Physiological Psychology, in press.

BOLLES, R. C., STOKES, L. W., \& YOUNGER, M. S. Does CS termination reinforce avoid ance behavior? Journal of Comparative \& Physiological Psychology, 1966, 62, 201-207.

\section{NOTE}

1. Supported by National Science Foundation Grant GB-8035.

\section{Motivation and learning in a water maze}

\section{CONSALVI, American University of Beirut, Beirut, Lebanon}

Studies of the learning behavior of rats in a water maze are presented. A total of 135 Ss, in 12 groups, were subjected to water temperatures from 60 to $110 \mathrm{deg} F$. Performance was assessed in terms of percentage of leamers, trials, errors, and time for each temperature. The results suggest that learning is a nonmonotonic function of temperature with peak performances in the regions of 80 and $110 \mathrm{deg}$. while motivation increases unidirectionally as water temperature diverges from that of the body.

This is a report of three separate studies of the leaming behavior of rats in a water maze that was designed and constructed by the writer. The project was initiated in order to provide a task for drug studies in which the difficulty level could be varied, massed trials applied, and motivation manipulated without recourse to deprivation schedules or shock.

A number of studies have appeared in which the behavior of rats or mice has been examined in a task involving swimming. The apparatus employed has consisted of swimways, fixed $T$-mazes, or water versions of the Lashley III; in general, these tasks have not permitted variation in difficulty level. Of interest here are several studies of learning and motivation as a function of water temperature. (All temperatures will be cited in Fahrenheit units throughout this paper.)

Wever (1932) studied the effects of eight water temperatures between 50 and $113 \mathrm{deg}$ on the time scores of rats in a swimway and found that trial time increased as temperature increased from 50 to $104 \mathrm{deg}$ and decreased at $113 \mathrm{deg}$.

Hack (1933) exposed rats to three temperatures in a simple water maze, 59 , 99.5 , and $113 \mathrm{deg}$. The lowest temperature showed the fastest drop in time scores and the highest produced about the same time scores though with a few more trials. The 99.5-deg group maintained much higher scores than either of the other two groups.

Waller et al (1960) used three groups of mice in a simple maze at three water temperatures, $68,80.6$, and $93.2 \mathrm{deg}$. They found that time scores differed significantly as a function of temperature on the 1 st day and continued to do so on the 12th day. Time increased with temperature for all groups. Over 12 days of testing, the groups at 68 and $80.6 \mathrm{deg}$ showed a decre ase in time scores, whereas the group at $93.2 \mathrm{deg}$ showed an increase. Error scores did not differ across groups as a function of temperature.

\section{APPARATUS}

The water maze consisted of a galvanized sheet-metal tank 96 in. long, 12 in. wide, 18 in. deep, which was separated into six compartments by five pairs of guillotine gates. A start box opened directly into the first compartment, and a ramp at the other end of the tank led to a heated platform. In each of the first five compartments, a sheet-metal baffle was mounted vertically between the two adjacent gates; this extended 4.5 in. into the compartment creating definite approaches (or blinds) to each of the gates. Above $70 \mathrm{deg}$, the water flowed through the tank continuously with the temperature controlled by a mixing valve. Temperatures below $70 \mathrm{deg}$ were established with ice and a continuous flow was not possible. (The maze contained $8 \mathrm{cu} \mathrm{ft}$ of water and heat transfer was slow.) PROCEDURE

At the start of each trial, $\mathrm{S}$ was lowered into the water, and the trial time recorder was started. $S$ was permitted to swim in each compartment until his body, exclusive of the tail, was situated in the approach to the correct gate; $\mathrm{E}$ raised the gate and $\mathrm{S}$ swam into the next compartment. If $S$ failed to 